\title{
Coping with Lengthy Ballots
}

\author{
J. Drew Seib \\ Department of Political Science and Sociology \\ Murray State University \\ Murray, KY 42071 \\ jseib@murraystate.edu
}

phone: 270-809-2695

fax: 270-809-1688 


\begin{abstract}
Given voters' limited cognitive abilities, the learning environments voters face may have implications for how voters learn and make decisions. One prominent feature of American elections is the variation in the length of the ballot across jurisdictions and elections. This paper explores the consequences of lengthy ballots on the ability of voters to learn about candidates. Using an experimental design and a dynamic information board (Lau and Redlawsk, 2006), subjects participate in a mock election where they are asked to gather information about a single election or multiple elections. The results indicate that while voters compare more information as ballot length increases, they spend significantly less time learning about individual pieces of candidate information.
\end{abstract}

Key Words: voters; campaigns; information search; elections; ballot length; experiment 


\section{Introduction}

Lost in the large number of elections America uses for public office are significant variations in the number of choices, salience, and information that citizens must consider when they make a decision. From one election to the next and one jurisdiction to another, voters can face substantially different learning environments. These differences in campaign environments may affect the ability of voters to gather enough information to make reasoned decisions. Normative theories expect voters to make well-reasoned decisions-to gather as much information as possible and compare information across alternatives. Moreover, political scientists have long complained about the lack of information that voters have and its consequences for elections.

Yet, it is possible that the design of the American electoral system is too demanding, given the cognitive limitations of voters, and the ability of voters to gather information in a rational manner is compromised by the context of the learning environment. Consider the 2012 elections in Tampa, Florida, and Lynchburg, Virginia. One precinct in Tampa had 37 items on the ballot (23 electoral contests and 14 state amendments). In comparison, a precinct in Lynchburg had a much shorter ballot with a total of five items on the ballot ( 3 electoral contests and 2 state amendments). While ballots at these two precincts are starkly different in their length and content, they do share one commonality. Voters at both precincts could cast a vote for the president of the United States.

Given the drastic difference in the number of choices voters are asked to make in Tampa and Lynchburg, do voters gather information differently for presidential candidates? One can imagine a voter in Tampa behaving quite franticly as he/she tries to gather enough information to make a reasoned decision for each office on the ballot. Voters in Tampa potentially had less time 
than voters in Lynchburg to devote to learning about the president, unless they decided to forgo learning about other items on the ballot. Even if voters in Tampa wanted to focus on just the presidential candidates, they still have more information to sift through in order to find information about the presidential candidates.

The number of offices on the ballot has largely been overlooked in the decision-making and information search literature. Most of the emphasis on ballot length has examined the consequences for down ballot elections (Selb, 2008; Bowler, Donovan and Happ, 1992;

Brockington, 2003), ignoring the consequences for the top of the ballot when voters become overwhelmed with choices. Being such a prominent characteristic of American elections, it is surprising that such little attention has been devoted to the relationship between ballot length and the decision-making process.

This paper examines the consequences of lengthy ballots on the ability of voters to learn about candidates. Results suggest that the length of the ballot affects the way voters search for and gather information. To examine the effects of ballot length on how voters acquire information, participants were randomly assigned to one of two campaigns. Participants in the first group were assigned to a campaign where they only had to learn about two candidates running for president. Participants in the second group learned about two candidates for each of seven offices and three statewide propositions. The results show that as the length of the ballot increases, voters become frantic, struggling to manage time and using different search and acquisition strategies. 


\section{Ballot Length}

Much of the literature on ballot length focuses on awareness (knowledge) and vote choice with little concern for how voters acquire information. However, if ballot length affects awareness and choice, then it is likely that it affects other parts of the decision-making process. As Jerit, Barabas and Bolsen (2006) note, the context of the campaign affects the knowledge that voters possess. With concurrent campaigns, the opportunity to learn about candidates decreases as campaigns vie for voters' attention. In choosing to learn about a piece of information for a candidate in one election, a voter may be giving up the opportunity to learn information about a candidate for another election. After all, a voter cannot watch two campaign commercials at once or attend two campaign rallies at the same time. If this is the case, then there should be differences in acquisition, retention, and choice.

Unlike much of the literature on concurrent elections, Wolak (2009) does not focus on the bottom of the ballot or low salience elections. Rather she examines voters' knowledge of candidates for the U.S. House of Representatives, given possible concurrent elections for the president, the U.S. Senate, and governors' offices. Wolak (2009) finds mixed results for the effects of concurrent elections on knowledge about the candidates. Her results indicate the presence of a presidential race does not affect the ability of voters to recall the names of candidates for House of Representatives races. However, in non-presidential election years, the results are much more nuanced. Concurrent Senate races help voters recall the names of House candidates and increase the ability of voters to place the candidates ideologically. However, the presence of a gubernatorial race in a non-presidential election year does not affect the ability of voters to recall the names of House candidates but does decrease the ability of voters to identify the ideological direction of House candidates. What is more, an intense gubernatorial campaign 
leads voters to mention fewer things they like (another proxy for knowledge) about a House incumbent and mention more things they like about a House challenger. Taken as a whole, Wolak's (2009) work suggests that in the presences of concurrent campaigns, voters gather information differently. The presence of concurrent campaigns alters the opportunities that voters have to learn about information, leading to a shallower search in some instances, as reflected in the low levels of knowledge about the candidates during concurrent campaigns.

However, this study is still limited in what it is able to say about how concurrent elections affect knowledge levels. Like most work on concurrent elections, it does not examine the possibility that a lower salience office affects knowledge levels of a higher salience office. As Nicholson $(2005,3)$ notes, many studies "exaggerate the individuality and disconnectedness of voting decisions across issues and candidates on the ballot." Evidence suggests that ballot propositions can prime issues in elections at the top of the ballot (Nicholson 2003) and the presence of ballot measures effect the criteria voters use to evaluate candidates further up the ballot (Nicholson 2005). This implies that the bottom of the ballot may be just as important for voter knowledge as the top of the ballot. Nicholson examines this in a number of contexts, including a natural experiment where he looks at the role of nuclear freeze ballot measures on vote outcomes. One of the interesting findings here is that the ballot measure impacted votes for congressional, senatorial and gubernatorial candidate, regardless of whether the candidate campaigned on the issue.

Both Nicholson's (2003 \& 2005) and Wolak’s (2009) work support the idea that campaigns do not happen in isolation - that contest for other offices matter for how people learn about candidates and make decisions. Lower level offices can detract from the attention that top of the ballot offices normally receive and, in some cases, set the agenda (Nicholson, 2005). This 
split attention that votes devote to various contest means that their cognitive resources may become spread thin and require making trade-offs.

\subsection{Should Ballot Length Matter to Information Searches?}

The small literature on ballot length and voter awareness and knowledge suggests that ballot length may alter the way voters gather information, but scholars have yet to examine this relationship in a political setting. Most studies on information searches focus on how a voter behaves in a single election or how a consumer searches for information about a single product class (Jacoby et al., 1976; Lau and Redlawsk, 2006; Redlawsk, 2004; Lau, 1995; Moore and Lehmann, 1980). Yet one of the distinct features of American elections is the variation in the number of elections, indeed competitive elections, across jurisdictional lines. While scholars have varied the number of products or candidates available to understand how increasing the complexity of the information environment alters the information search (Lau and Redlawsk, 2006), scholars have yet to consider how the number of product classes or electoral contests that people are asked to learn about might affect the way people search for information. During the typical campaign season, there are multiple contests on the ballot that span from the local to national level. This means that voters need to gather information for each decision that is to be made on Election Day if they are to make a well-reasoned decision for each item on the ballot. Yet, voters have limited resources, both in terms of time (Downs, 1957; Brady, Verba and Schlozman, 1995) and cognitive abilities (Simon 1956; Miller 1956). These limitations may lead voters to forgo learning about some information or alter the way they gather information.

While scholars have yet to explore how the number of contests on the ballot affects how voters gather information or make decisions, increasing the number of candidates running for an 
office and the number of offices on the ballot are both examples of increased task complexity. These two examples can be distinguished as horizontal task complexity (adding candidates) or vertical task complexity (adding offices). As Payne, Bettman and Johnson (1992, p. 90) note, "characteristics of the decision problem...can evoke different [decision] strategies that at least partially determine the preferences and beliefs we observe." The literature on task complexity is consistent. As task complexity increases, people are more likely to rely on noncompensatory strategies (Einhorn, 1971; Tversky, 1972, Lau and Redlawsk 2006). In fact, "a major determinant of which strategy will be used in a task is task complexity" (Payne, 1982, p. 386).

In political science, scholars have demonstrated that the number of candidates running for an office affects the decision strategies that voters use (Lau and Redlawsk, 2006) and the evaluation of candidates (Riggle, 1992; Lau and Redlawsk, 2006). Lau and Redlawsk (2006) find that voters in a primary election who have four candidates to learn about have a deeper, less comparable, and less ordered search than voters who only have to learn about two candidates. Riggle (1992) also demonstrates that as the number of candidates on the ballot increases, voters tend to rely more heavily on the party identification of the candidates for their evaluations. This suggests that as the environment or task becomes more complex, voters rely more heavily on simplifying strategies rather than using compensatory strategies. It also indicates that their search is likely not as deep, and voters are not comparing as much information and instead relying on the simple comparison of Democrat versus Republican.

However, the number of candidates running for an office and the number of offices on the ballot are distinct phenomena. When an additional candidate is added to a race, the choice set is changed. The voter must now evaluate and compare an additional candidate, which may change judgments and decisions about the original set of candidates. For example, in 1992 voters 
had three candidates to consider: Ross Perot, George H.W. Bush, and Bill Clinton. By contrast, voters only had to learn about Mitt Romney or Barack Obama in 2012. A voter had an additional candidate to learn about in 1992. In either 1992 or 2012, the process of searching for information is relatively easy if the voter is only learning about presidential candidates. The voter must only ask which candidate and which piece of information or attribute he/she wants to learn about.

In contrast, when more offices are added to a ballot, the choice set for offices on the original ballot does not change, but an additional layer is added to the choice set. Using the 2012 contest between Mitt Romney and Barack Obama again, no matter how many contests there are on a ballot in a given precinct, there are no additional candidates to learn about for president. The choice between Barack Obama and John McCain remains the same no matter where a person lives in the United States. What does change is the number of other offices that a voter must consider in addition to the president. Thus, a person must now decide which contest, candidate, and piece of information or attribute to learn about.

Moreover, prior research demonstrates the inability of people to handle complex sets of information (Miller, 1956; Cowan, 2001). Cowan (2001, pages 88-89) even goes on to layout some conditions under which people reach their cognitive limits to process information. These include when there is an information overload that prevents a person from committing information to long-term memory and when the information environment prevents a person from organizing or categorizing information. The multi-layered process of gathering information about candidates limits voters' ability to group information and organize it, and voters are often left with individual stimulus items. Moreover, the amount and fast flow of information during a campaign can lead to an information overload. 
The multilayered process inherently makes it more difficult for voters to process information, given their limited cognitive capacities. A voter may choose to examine one piece of information about a presidential candidate, but then when offered the chance to learn about candidates for other offices can no longer manage the information. Imagine a scenario where there 7 offices on the ballot. If a person is only able to handle seven plus or minus two chunks of information at a given time (Miller, 1956), then seven elections, which is on the low end in ballot length in the United States, is already maxing out a voter's cognitive capacity. Moreover, bouncing between elections makes it more difficult for voters to group information into larger chunks of information. A voter is not able to focus on a single election and group that information together, but rather gathers individual chunks of information for each election. One could now imagine a voter becoming quite frantic as they attempt to adapt to the complex environment. Ceteris paribus, the addition of another layer to the decision task (additional offices) may alter the way voters gather information about candidates for a given office.

There is some evidence that vertical task complexity matters. Early research on ballot length examined the role of ballot length on vote outcomes. One of the electoral policy concerns that came out of these studies was the finding that the order of the candidates on the ballot matters, especially when the candidates are not well known and the race is toward the bottom of the ballot (Taebel 1975). Taebel's (1975) finding is consistent with research on direct legislation elections where ballots are known to be lengthy. As the ballot gets longer, voters are less likely to be aware of propositions on the ballot (Nicholson, 2003) and, even more so, they are less likely to cast a "yes" vote in support of the proposition and instead vote to retain the status quo (Selb, 2008). In addition, McDermott (1995) finds that in low information elections, voters tend to rely more heavily on simplifying cues. 
These findings suggest that by simply increasing the length of the ballot we can change how much information a voter has about a particular item on the ballot and possibly affect the voter's choice. However, it is difficult to distinguish task complexity from fatigue in this particular case-that is how do we know if voters are becoming tired of learning about items on the ballot or if they are consciously choosing to not to learn about some items and focus on the ones they find most important? Moreover, just because voters are less informed as ballot length increases does not mean that they cannot cope and adapt their search behavior to the environment.

\subsection{Expectations}

There are several expectations regarding the relationship between ballot length and voter information searches. First, as task complexity increases, there is a greater need to simplify the decision environment. This implies that as the length of the ballot increases voters will be less likely to use a compensatory strategy and more likely to use a noncompensatory strategy. As soon as voters have the added layer of also deciding which office to learn about, in addition to which candidate and piece of information, the environment will become overly complex. This will make it more difficult to use a compensatory strategy and make value trade-offs.

Second, because voters' need to simplify the environment when there are many contests on the ballot, they will rely on pieces of information that have the greatest benefit with the smallest cost-the candidates' party affiliation. Thus, as the number of offices on the ballot increases, voters should access the party affiliations of the candidates more frequently.

Third, an increase in task complexity should also lead to greater uncertainty surrounding the decision (Dhar, 1996). This means that as the number of offices on the ballot increases, 
voters will need to search for more information about the candidates in order to have a sufficient level of certainty to make the decision-or in other words saticfice. Thus, the number of pieces of information examined should increase as the number of contests on the ballot increases. However, as voters struggle to handle the more complex environment that lengthy ballots present, the amount of time voters spend examining individual pieces of information will decrease.

Fourth, since voters are expected to examine more pieces of information, but compare less information, the search must be directed more toward one of the candidates. Prior research has demonstrated that people tend to be biased toward information that is consistent with their preferences, including when they are searching for information (Schulz-Hardt et al. 2000). This is in line with expectations of a confirmatory and a heuristic-based search, where by the voter learns the party affiliations of the candidates and the searches for enough information about their preferred candidate until they are comfortable that the party-label fits the candidate (see Lau and Redlawsk 2006). This would be consistent with Lau and Redlawk's (2006) findings in primary campaigns with two versus four candidates where the in-party candidate receives comparatively more attention than the out-party candidate when there are four candidates. Given the importance of partisanship, especially in more complex information environments, voters should direct their search toward the in-party candidate. This means that as ballot length increases, voters will examine more pieces of information for the in-party candidate.

Fifth, since an increase in the number of offices on the ballot increases the complexity of the environment, voters will struggle to manage their search for information. As such they will need to find ways to manage the environment. "When information is easily managed, a structured [search] strategy may not be needed" (Redlawsk 2004, 600). Indeed, Redlawsk 
(2004) does find some evidence that with more candidates running for president voters have a more structured (less random search), though his evidence is mixed. This means that as task complexity increases, the search for information about the candidates should become less random. Voters who face longer ballots should have a smaller proportion of intra-candidate, intra-alternative and inter-candidate, inter-alternative searches than voters who face shorter ballots.

\section{Methods}

How voters gather information is difficult to study, especially in the real world. It is not feasible to monitor voters during a campaign and record all of the campaign information that they encounter (Beatty and Smith, 1987). Likewise, asking voters what kinds of campaign information they encountered during a political campaign is a better reflection on what is in a person's working memory than what they searched for (Lau and Redlawsk, 2006). Thus, experiments and process tracing prove to be useful tools for studying how voters gather information or any part of the decision-making process for that matter. Furthermore, an experiment gives the researcher control over the content and design of the campaign. This allows the researcher to manipulate the number of offices on the ballot, while isolating out other possible explanations.

\subsection{Experimental Overview}

In order to study how voters search for information, this study used a dynamic information board, modeled after Lau and Redlawsk (2006). The dynamic information board simulated a campaign by presenting participants with information about the candidates and a process-tracing method tracked what pieces of information participants chose to view and in what order. Participants were recruited through Amazon Mechanical Turk and paid \$18 upon 
completion of the study. When a participant decided to participate, they began by reading a consent form. Next, participants took a short survey in order to gather some background information on them. Then, participants had a chance to acclimate to the dynamic information board. Next, participants read some additional instructions about how the dynamic information board was set up for the mock campaign and were presented with a scenario that set the stage for the mock campaign. After reading the scenario, participants proceeded to the mock campaign, which presented participants with information via the dynamic information board, described below. Finally, participants voted and took a post-survey, which included a manipulation check. On average, it took participants just under an hour to complete the study.

\subsection{Experimental Manipulation: Number of Offices on the Ballot}

In order to test how the number of elections on the ballot affects voter information searches, participants were randomly assigned to one of two conditions. In the first condition, participants only had to learn about two candidates running for president. In the second condition, participants had the opportunity to learn about two candidates for each of the seven offices on the ballot (president, senate, congress, governor, state legislator, state supreme court judge, and mayor) and three statewide propositions (deceased candidate procedure, term limits for Congress, and redistricting procedures). Because statewide propositions have been shown to prime voters (Nicholson, 2003), the candidates in the mock campaign did not discuss the issues surrounding the statewide propositions. For example, one of the propositions deals with what to do in the case of a deceased candidate, but this issue is never addressed by any of the candidates during the mock campaign. In trying to keep the campaign as realistic as possible, the amount of information available for each campaign varied by election. In other words, there was more information available for the presidential campaign than the senatorial campaign and so forth 
down to the mayoral campaign. However, it is important to note that the same amount and type of information was available for the presidential candidates in both conditions. Since over all there was more information available in the condition with multiple offices up for election, participants were given the same amount of time per box that scrolled down the information board, thus holding time constant between the two conditions. In order to give a real value to each of the offices beyond the label, participants were asked to rank order each of the offices. They are then told that following the mock campaign they may be tested and that the probability of getting a question about any one candidate or office is based on their ranking of the offices.

\subsection{The Dynamic Information Board}

The information board used in this study is modeled after Lau and Redlawsk (2006). As Lau and Redlawsk (2006) note, a dynamic information board is more appropriate for studying elections than a static information board because the information available during an election cycle is constantly changing. For example, candidate characteristics (education, experience, family, religion) tend to be more prevalent than horse race and hoopla (polls, debates, and campaign rallies) at the beginning of the campaign. Conversely, candidate characteristics are less prevalent during the second half of a campaign than horse race and hoopla (Lau and Redlawsk, 2006).

The information board in this study mimicked this characteristic of campaigns. Content for the information board was gathered from newspapers and Internet sources and simulated the type of information typically available for each type of campaign (presidential, senatorial, congressional, gubernatorial, state supreme court, state legislator, mayoral, and three statewide propositions). The information board has two main areas: a set of scrolling boxes in the middle of the screen and a timer that counts down to "Election Day" (see Figure 1). At any given time 
there are five boxes on the screen. Each box is labeled to describe the information behind it. For example, a box labeled “John Mallory’s Position on Immigration” would contain a short speech made by the candidate or a selection from a newspaper article about John Mallory's position on immigration. If a participant clicks on a box, a new window opens that takes up the entire computer screen (see Figure 2). The participant reads the information and then clicks on the "Finished" button to close the window. The computer records which pieces of information were accessed and how long the participant spent reading the information. Meanwhile, the boxes on the information board continue to scroll in the background. This means that by choosing to view one piece of information, a participant must give up the opportunity to view others.

[Insert Figures 1 and 2 about here]

The dynamic information board was very similar in both conditions. First, the font on both conditions indicates the party associated with the candidates. Information about the Democratic candidates was in a blue font and information about the Republican candidates was in a red font. Information that was party neutral or about both candidates was in a black font. The boxes were color-coded, but the participants had to figure out which color was associated with which race, a much easier task when there is only one office on the ballot.

While the dynamic information board for the condition with the two presidential candidates on the ballot is fairly straightforward, the condition with multiple offices is a little more complex. To mimic the dynamic nature of the typical campaign season, the first third of the boxes that scrolled down the screen were only about the presidential candidates. The secondthird of boxes that scrolled down the screen were about the presidential, senatorial, and 
congressional candidates. The last-third of boxes contained information about all the candidates and the three propositions. This also means that I am providing a tougher test of the hypotheses than if information about all offices had an equal chance of being available through out the entire campaign season, given that the campaign information for the first third of the election in both conditions only focus on the presidential candidates.

\subsection{Measurement}

Due to limitations in data, and the fact that subjects only had two possible campaigns environments that they could be assigned to (one with only a presidential race and one with the president plus eight other races (senate, congress, state legislative, governor, state supreme court, mayor, and three ballot propositions), the analysis is limited to search for information about the presidential candidates. This, however, permits a controlled comparison of how voters search for information about the same office in two different environments-one simple and one complex.

There are four key dependent variables for understanding how ballot length affects how voters search for information. The first variable is the depth of search. Depth of search is measured in two different ways, each of which tells us something different. First, it is measured as a count of the number of boxes the participants accessed. Second, depth of search can be measured as the average amount of time in seconds spent reading about any given piece of information. It describes how closely the participant examined the campaign information.

The second dependent variable is the comparability of search. It measures the proportion of information that was considered for both candidates. For example, if a participant views the party identification for Candidate A and Candidate B at least one time each, then this is coded as a comparable search on that attribute. The variable is measured as the number of attributes considered at least once for both candidates. The third dependent variable is the content of the 
search, which is a count of the number of times an attribute is accessed. This study is specifically interested in whether a participant accesses the party affiliations of the candidates.

The final dependent variable is the sequence of search, which corresponds to how the participant transitions from one piece of information to another. As demonstrated in Table 1, there are four possible transitions that a participant can make: intra-candidate, inter-attribute; intra-attribute, inter-candidate; intra-candidate, intra-attribute; and inter-candidate, inter-attribute. The first two are considered ordered or systematic searches, while the second two are considered random searches (Lau and Redlawsk, 2006). Although the authors do not explicitly state the reasoning for this classification, it goes back to the expectations for sequence of search for compensatory strategies. With an intra-candidate, inter-attribute transition, a subject would focus on one candidate at a time. For example, a participant could click on a box that is scrolling down the dynamic information board and read about John Malory's position on taxes. After closing the box, the participant then chooses to click on a box labeled John Malory's position on social security and read this information as well. Since the transition from one piece of information to another on the information board was to stay with the same candidate, but examine a different issue, the program records the transition as an intra-candidate, inter-attribute transition.

Similarly, a decision maker could have an inter-candidate, intra-attribute transition (different candidates, but same piece of information). Here the participant, for example, clicks on Bill Stark's position on taxes and reads the related information. Next the participant clicks on John Mallory's position on taxes and learn about his position. Here the participant focused on the same piece of campaign information for two different candidates, so the program will record this transition as an inter-candidate, intra-attribute transition. 
The two remaining strategies are considered haphazard or random transitions because they indicate that the decision-maker is searching for information in an unsystematic way. In an intra-candidate (same candidate), intra-attribute transition (same attribute/campaign information), a participant, for example, clicks on and reads about Bill Stark's position on education and then clicks on and rereads Bill Stark's position on education a second time. The program will record this as an intra-candidate, intra-attribute transition.

In an inter-candidate, inter-attribute transition, a participant may click on Bill Stark’s position on taxes and read about his position. Next the participant clicks on John Mallory's position on education and learns about John Mallory's position on education. Notice that the participant started with one candidate and issue and the transitioned to a different candidate on a different issue. When this happens, the program records this as an inter-candidate, inter-attribute search.

\section{[Insert Table 1 here]}

Lau and Redlawsk use two measures of sequence of search, one that captures the ratio of alternative to attribute-based searches and one that captures the amount of systematic searches. As Lau and Redlawsk (2006) note, examining the amount of alternative-based transitions is only useful in specifying the specific strategy (e.g. additive linear rule versus additive difference) and does nothing to distinguish between compensatory and noncompensatory strategies, which is of more concern here. The additive linear rule and the additive difference are both compensatory strategies. People who use either of these strategies have a deep search, compare as much information as possible, and transition from one piece of information to another in an orderly 
fashion. The only thing that distinguishes these two searches is the amount of alternative-based transitions (search for information about one candidate at time) versus the amount of attributebased transitions (search for information about one attribute at a time for all candidates). The additive linear rule is an alternative-based strategy, while the additive difference is an attributebased strategy. However, examining the amount of alternative-based search is a better measure of how information is organized in people's minds (Rahn 1996), which is not the focus of this study.

This study examined how people adapt to information environments and thus Lau and Redlawsk's (2006) second measure of sequence of search is more important. Lau and Redlawsk (2006) measured the amount of systematic search as the sum of the amount of intra-attribute and intra-candidate transitions. However, to be clear, they only considered the intra-candidate, interattribute transitions and inter-candidate, intra-attribute transitions to be systematic. Thus, I measured the amount of systematic search as the percentage of intra-candidate, inter-attribute and inter-candidate, intra-attribute transitions. To do this, I took the sum of the number of intracandidate, inter-attribute and inter-candidate, intra-attribute transitions and divided it by the number of possible transitions. ${ }^{1}$

(intra-candidate, inter-attribute transitions $)+($ inter-candidate, intra-attribute transitions) total number of transitions

1 The total number of transitions is equal to the depth of search minus one. 


\subsection{Control Variables}

While the primary focus was the length of the ballot, I also controlled for other possible factors that may explain information search patterns. ${ }^{2}$ First, I controlled for the strength of a participant's partisanship on a scale from 0 to 3 , with 0 corresponding to independents, and 3 corresponding to strong partisans. Second, I controlled for participants' interest in politics. Participants were asked "How interested are you in information about what's going on in government and politics?" with responses anchored by "not at all interested" (1) and "extremely interested" (5). Finally, I controlled for participants' level of political knowledge using the standard 5-item knowledge test. This variable is the percentage of questions that the participant answered correctly on a scale from 0 to 1 .

\section{Results}

There were a total of 206 participants who completed the study. Table 2 shows that there were not any significant differences in demographics across the two conditions. According to the results in Table 2, the sample is almost evenly split between men and women. Most of the sample was white, and has as at least started college or has a college degree. Politically, the sample tends to be slightly Democratic and liberal. The average participant reports to be moderately interested in politics. Finally, the average participant scored about a $75 \%$ on a standard political knowledge test.

[Insert Table 2 about here]

2 The variance inflation factors (VIFs) for the control variables range between 1.0 and 1.15.

Since the VIFs are so small, there is little reason to be concerned with multicolinearity. 


\subsection{Manipulation Check}

Based on a t-test of the manipulation check, participants perceived a difference in the two conditions, as shown in Figure 3. When participants were asked to rank how difficult it was to gather information, participants reported that it was more difficult to gather information about candidates when there were more offices on the ballot. On a scale from one (very easy) to five (very difficult) participants in the condition with more offices on the ballot reported that gathering information was between somewhat difficult and in between, while participants who only had to learn about the president reported that gathering information about candidates was between somewhat easy and in between. Thus, as ballot length increases, participants report to find it more difficult to search for and gather information. This initial finding, based on participant's self-reported assessment of the environment, suggests that concurrent elections make it more difficult for voters to handle the information environment.

\section{[Insert Figure 3 about here]}

\subsection{Differences in the Search for Information}

Table 3 presents the results of a series of t-tests for each of the dependent variables by condition. There are several interesting, significant findings in Table 3. First, participants spent significantly less time, on average, examining information. Participants with the short ballot spent about 13 seconds on any given piece of information, while participants with the long ballot

only spent about 8 seconds per item they examined. Second, participants assigned to the condition with the long ballot compared more information. In fact, they compared twice as much 
information as participants in the condition with the short ballot. Finally, although slightly insignificant, participants with the long ballot appear to have a more systematic search.

A more detailed examination of voters' ability to handle the information environment is presented in Table 4. Since depth of search (number of items accessed), comparability of search, content of search, and in-party and out-party search are all count variables, they are analyzed using a Conway-Maxwell Poisson Regression. ${ }^{3}$ The Conway-Maxwell Poisson coefficients can be interpreted by taking the coefficient divided by the conditional variance $(v)$. The remaining variables, depth of search (time spent examining information) and sequence of search, are analyzed using an OLS regression.

The results found in Table 4 are similar to those in Table 3 and demonstrate the robustness of the findings. Just like in Table 3, nothing predicts how many items in the information board a person examined. There were no statistical differences between those who had the long or short ballot. There were, however, differences in how long a participant spent on average examining a piece of information. Participants who were assigned to the longer ballot spent 4.563 seconds less examining any given individual piece of information. This is quite significant, especially given the baseline for this model is approximately 13 seconds. The difference represents more than a one-third reduction in time spent learning and demonstrates that under the longer ballot condition, even though participants examined the same number of items as participants in the short ballot condition, they examined the information less closely.

3 The Conway-Maxwell Poisson Regression is a versatile regression model for count data. It can handle both over and under dispersion and usually performs better than other count models. For a more complete review see Sellers and Shmueli (2010). 
The results in Table 4 also show that comparability of search is affected by ballot length. However, instead of participants comparing more information when the ballot was shorter, participants compared more information under the longer ballot condition. When faced with the longer ballot, participants compared $97 \%$ more information, which is contrary to the expectation for this variable. What also makes this finding interesting is that this is not due to how many pieces of information were examined, since participants in the two conditions examined the same number of items on average. In addition, those who were more interested in politics were also more likely to compare more information.

The effect of ballot length on how many times participants accessed the party affiliations of the candidates was insignificant. However, strong partisans and the less politically sophisticated were more likely to examine the party affiliations of the candidates, demonstrating their reliance on this piece of information. The remaining models for sequence of search, inparty search, and out-party search are also insignificant, though strength of partisanship did have a statistically significant effect in determining how many pieces of information a participant examined for the out-party candidate.

\section{Discussion}

The findings here show that ballot length is important in shaping how voters gather information. Voters, when faced with a longer ballot, examine information less closely but compare more information. In other words, voters try to learn about candidates even when faced with more contests, but fail to manage their greatest resource, time, efficiently.

The search and acquisition patters of participants in this study are indicative of a noncompensatory search. Specifically, it suggests that voters are either using an elimination by aspect or fast and frugal strategy when faced with the more complex environment of lengthy 
ballots. What is striking though, is that this occurs at the top of the ballot with the president. The presidential campaign is the most salient and most familiar of all the contests on the ballot, and yet even here voters have to compensate for the complexity of the choice environment.

This study also helps explain findings in earlier works of ballot length and knowledge. Research such as Wolak (2009) suggests that ballot length matters for how easily voters can recall information about candidates, even for relatively prominent contests such as senatorial or congressional elections. Even in salient elections, voters still have to make tradeoffs and these tradeoffs have consequences for how voters gather information and cognitively organize that information.

The results also suggest that voters may not bare all the responsibility for their lack of knowledge of candidates, even presidential candidates. If voters are faced with so many contests in an election (in the case of this study only seven offices plus three state-wide propositions) that they struggle to handle the information in an efficient manner, then it may suggest that we need to think critically about the way the electoral system is designed. The goal should be to provide an environment in which voters can make good decisions, but this implies that voters operate in an electoral environment where it is easy to gather information about the candidates running for an office. This study suggests that long ballots make this difficult, even for important races such as the president.

Finally, this study is also suggestive for other electoral contests with long ballots. Given that longer ballots tend to feature offices that are lower salience and voters tend to be less knowledgeable (Miller and Krosnick 1998; Darcy and McAllister, 1990), this study may begin to explain why. Even with high salience offices, such as the president, voters had to make tradeoffs and resort to non-compensatory strategies. This is important to note, especially since most 
of the literature on long ballots and ballot roll-off focuses on the bottom of the ballot. However, this study suggest that the top of the ballot is also affected. In addition, it also seems logical that this effect would be even larger going down the ballot, given the competition for voter's attention as salience decreases and the amount of information available for lower salience versus higher salience offices. However, more research is needed to understand the degree to which ballot length affect the search for information in lower salience contests.

\subsection{Shortcomings}

While this study presents evidence that ballot length matters for how voters gather information, the data was gathered in an unnatural environment. When voters gather information, typically it is not in front of a scrolling set of boxes. Moreover, this study used a mock campaign. But, it is important to keep in mind the advantages of experiments. They permit researchers to control every aspect of the decision-making environment and monitor participants as they more through a study. The campaign in this study was constructed to mimic a real campaign as close as possible, including the fast flow of information during a campaign and campaign content for each office.

\subsection{Future Research}

While this study has filled a gap in ballot length research, there is still much to learn. One major question related to this study is does ballot length ultimately affect the quality of decisions that voter's make - in other words, when faced with long ballots do voters still vote consistently with their preferences. Likewise, there are a number of other contexts in the American electoral system (and other electoral systems) that are important to explore. For example, does the lack of partisan information in nonpartisan elections alter the way voters gather information? Does it indeed encourage voters to become more informed about information or do voters find partisan 
cues imbedded in the information? Does the number of competitive parties matter for how voters gather information? How does ballot length affect information-seeking behavior in low salience elections, such as ballot measures? These are just a few examples of what political scientists still have yet to explore.

\section{Acknowledgements}

I would like to thank the National Science Foundation for their support. This project is based upon work supported by the National Science Foundation under Grant No. SES1023239. I would also like to thank Scott McClurg, Tobin Grant, Phillip Habel, Ken Mulligan, Mike Young, Jeremy Phillips, Antonio Rodriguez, and Matt Bergbower for their helpful comments on previous drafts. All errors remain the sole responsibility of the author. 


\section{References}

Bowler, S., Donovan, T. \& Happ T. (1992). Ballot propositions and information costs: Direct democracy and the fatigued voter. Political Research Quarterly, 45(2), 559-568.

Brady, H. E., Verba, S., \& Schlozman, K. L. (1995). Beyond ses: A resource model of political participation. The American Political Science Review, 89(2), 271-294.

Brockington, D. (2003). A low information theory of ballot position effects. Political Behavior, $25(1), 1-27$.

Cowan, N. (2001). The magical number 4 in short-term memory: A reconsideration of mental storage capacity. Behavioral and Brain Sciences, 24(01), 87-114.

Darcy, R. \& McAllister, I. (1990). Ballot position effects. Electoral Studies 9: 5-17.

Dhar, R. (1996). The effect of decision strategy on deciding to defer choice. Journal of Behavioral Decision Making, 9(4), 265-281.

Downs, A. (1957). An Economic Theory of Democracy. New York: Harper and Row.

Einhorn, H.J. (1971). Use of nonlinear, noncompensatory models as a function of task and amount of information. Organizational Behavior and Human Performance, 6(1), 1-27.

Jacoby, J., Chestnut, R.W., Weigl, K.C., \& Fisher, W. (1976). Pre-purchase information acquisition: description of a process methodology, research paradigm, and pilot investigation. In B. Anderson (Ed.) Advances in Consumer Research. Paper presented at Association for Consumer Research North American Conference, Ohio (3:306-314).

Jerit, J., Barabas, J. \& Bolsen, T. (2006). Citizens, knowledge and the information environment. American Journal of Political Science, 50(2), 266-282.

King, G. (1998). Unifying political methodology: The likelihood theory of statistical inference. Ann Arbor, MI: University of Michigan Press. 
Lau, R.R. (1995). Information search during an election campaign: Introducing a processingtracing methodology for political scientists. In M. Lodge and K. M. McGraw (Eds.), Political judgment: Structure and process.

Lau, R.R. \& Redlawsk, D.P. (2006). How voters decide: Information processing during election campaigns. Cambridge. MA: Cambridge University Press.

Miller, G. A. (1956). The magical number seven, plus or minus two: Some limits on our capacity for processing information. Psychological Review, 63(2), 81 - 97.

Miller, J.M. \& Krosnick, J.A. (1998). The impact of candidate name order on election outcomes. Public Opinion Quarterly 62: 291-330.

Moore, W.L. \& Lehmann, D.R. (1980). Individual differences in search behavior for a nondurable. Journal of Consumer Research, 7(3), 296-307.

Nicholson, S.P. (2003). The political environment and ballot proposition awareness. American Journal of Political Science, 47(3), 403-410.

Payne, J.W. (1982). Contingent decision behavior. Psychological Bulletin, 92(2), 382-402.

Payne, J.W., Bettman, J.R., \& Johnson, E.J. (1992). Behavioral decision research: A constructive processing perspective. Annual Reviews in Psychology, 43(1), 87-131.

Redlawsk, D.P. (2004). What voters do: Information search during election campaigns. Political Psychology, 25(4), 595-610.

Riggle, E.D. (1992). Cognitive strategies and candidate evaluations. American Politics Research, 20(2), 227-246.

Selb, P. (2008). Supersized votes: Ballot length, uncertainty, and choice in direct legislation elections. Public Choice, 135(3), 319-336. 
Sellers, K. F., Shmueli, G. (2010). A flexible regression model for count data. Annals of Applied Statistics, 4(2), 943-961.

Schulz-Hardt, Stefan, Frey, D., Luthgens, C., \& Moscovici S. (2000). Biased information search in group decision making. Journal of Personality and Social Psychology, 78(4): 655-669.

Simon, H.A. (1956). Rational choice and the structure of the environment." Psychological Review, 63(2), 129.

Tversky, A. (1972). Elimination by aspects: A theory of choice. Psychological Review, 79(4), 281-299.

Wolak, J. (2009). The consequences of concurrent campaigns for citizen knowledge of congressional candidates. Political Behavior, 31(2), 211-229. 
Table 1: Sequence of Search

\begin{tabular}{|l|l|l|}
\hline & Inter-Candidate & Intra-Candidate \\
\hline Inter-Attribute & New Candidate, New Attribute & Same Candidate, New Attribute \\
\hline Intra-Attribute & New Candidate, Same Attribute & Same Candidate, Same Attribute \\
\hline
\end{tabular}


Table 2: Demographics by Condition

\begin{tabular}{rccc}
\hline & Short Ballot & Long Ballot & p-value \\
\hline Female & 0.54 & 0.48 & 0.41 \\
White & 0.80 & 0.80 & 0.92 \\
Education & 3.31 & 3.47 & 0.14 \\
Interest & 3.35 & 3.45 & 0.52 \\
Party Id & 3.37 & 3.37 & 0.92 \\
Ideology & 3.46 & 3.36 & 0.65 \\
Political & $73.68 \%$ & $75.58 \%$ & 0.39 \\
Knowledge & & & \\
\hline \hline
\end{tabular}


Table 3: T-Test of Condition and Dependent Variables

\begin{tabular}{rccc}
\hline & Short Ballot & Long Ballot & p-value \\
\hline Depth (Number of & 48.89 & 51.17 & 0.48 \\
Items) & & & \\
Depth (Time) & 12.97 & 8.22 & 0.001 \\
Comparability & 7.01 & 14.34 & 0.001 \\
Content (Party) & 3.55 & 3.27 & 0.47 \\
Sequence & 0.38 & 0.41 & 0.09 \\
In-Party & 18.60 & 20.00 & 0.35 \\
Out Party & 19.98 & 21.62 & 0.26 \\
\hline \hline
\end{tabular}


Table 4: Regression Models for Dependent Variables

\begin{tabular}{|c|c|c|c|c|c|c|c|}
\hline & 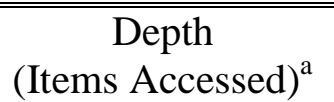 & $\begin{array}{l}\text { Depth } \\
\text { (Time) }{ }^{b}\end{array}$ & Comparability $^{\mathrm{a}}$ & $\begin{array}{l}\text { Content } \\
\text { (Party) }^{\mathrm{a}}\end{array}$ & Sequence $^{b}$ & In-Party $^{\mathrm{a}}$ & Out-Party $^{\mathrm{a}}$ \\
\hline Constant & $\begin{array}{l}0.270^{*} \\
(0.044)\end{array}$ & $\begin{array}{l}12.874 * \\
(1.873)\end{array}$ & $\begin{array}{l}0.165^{*} \\
(0.067)\end{array}$ & $\begin{array}{l}0.544^{*} \\
(0.162)\end{array}$ & $\begin{array}{l}0.369^{*} \\
(0.026)\end{array}$ & $\begin{array}{c}0.379 \\
(0.061)\end{array}$ & $\begin{array}{l}0.466^{*} \\
(0.066)\end{array}$ \\
\hline Long Ballot & $\begin{array}{c}0.004 \\
(0.007)\end{array}$ & $\begin{array}{c}-4.563 * \\
(0.927)\end{array}$ & $\begin{array}{l}0.165 * \\
(0.028)\end{array}$ & $\begin{array}{c}-0.053 \\
(0.058)\end{array}$ & $\begin{array}{c}0.022 \\
(0.013)\end{array}$ & $\begin{array}{c}0.012 \\
(0.014)\end{array}$ & $\begin{array}{c}0.036 \\
(0.024)\end{array}$ \\
\hline Partisan Strength & $\begin{array}{c}0.004) \\
(0.003)\end{array}$ & $\begin{array}{c}-0.174 \\
(0.481)\end{array}$ & $\begin{array}{l}-0.007 \\
(0.011)\end{array}$ & $\begin{array}{l}0.064 * \\
(0.030)\end{array}$ & $\begin{array}{l}-0.006 \\
(0.007)\end{array}$ & $\begin{array}{l}-0.003 \\
(0.007)\end{array}$ & $\begin{array}{l}0.024 * \\
(0.010)\end{array}$ \\
\hline Political Knowledge & $\begin{array}{c}0.012 \\
(0.015)\end{array}$ & $\begin{array}{c}0.023 \\
(0.021)\end{array}$ & $\begin{array}{c}0.001 \\
(0.001)\end{array}$ & $\begin{array}{c}-0.004 * \\
(0.001)\end{array}$ & $\begin{array}{c}0.014 \\
(0.008)\end{array}$ & $\begin{array}{c}0.023 \\
(0.031)\end{array}$ & $\begin{array}{c}0.016 \\
(0.032)\end{array}$ \\
\hline Interest In Politics & $\begin{array}{c}0.003 \\
(0.003)\end{array}$ & $\begin{array}{l}-0.613 \\
(0.447)\end{array}$ & $\begin{array}{l}0.007 * \\
(0.001)\end{array}$ & $\begin{array}{c}0.046 \\
(0.029)\end{array}$ & $\begin{array}{c}0.004 \\
(0.006)\end{array}$ & $\begin{array}{c}0.004 \\
(0.007)\end{array}$ & $\begin{array}{c}0.007 \\
(0.007)\end{array}$ \\
\hline $\mathrm{N}$ & 206 & 206 & 206 & 206 & 206 & 206 & 206 \\
\hline Log-Likelihood & -907.97 & & -648.49 & -448.25 & & -755.96 & -751.8 \\
\hline$v$ & 0.08 & & 0.17 & .48 & & 0.15 & 0.182 \\
\hline & $10.23 *$ & & $3.98 *$ & $1.92 *$ & & $5.87 *$ & $4.85^{*}$ \\
\hline \multicolumn{8}{|c|}{$\begin{array}{l}\text { a Conway-Maxwell Poisson Regression } \\
\mathrm{b} \text { OLS Regression } \\
* \mathrm{p}<0.05 \\
\text { Entries are unstandardized coefficients with standard error in parenthesis. } \\
\text { Long Ballot }=1 \text { for the condition with the long ballot and } 0 \text { for the condition with the short ballot. } \\
v \text { is the conditional variance in the Conway-Maxwell Poisson Regression Models } \\
\quad \text { is the dispersion parameter for the count variables. }\end{array}$} \\
\hline
\end{tabular}




\section{CAMPAIGN}

John Mallory's Age

Bill Strak's Position on the Death Penalty

Bill Strak's Slogan

John Mallory's Position on Poverty

Bill Strak's Political Party

TIME LEFT UNTIL ELECTION DAY

$08 \mathrm{~min}$ and $49 \mathrm{sec}$

\begin{tabular}{l} 
John Mallory's Age \\
\hline Bill Strak's Position on the Death Penalty \\
Bill Strak's Slogan \\
\hline John Mallory's Position on Poverty \\
\hline Bill Strak's Political Party \\
\hline TIME LEFT UNTIL ELECTION DAY and 49 SEC
\end{tabular}




\section{John Mallory's Position on Poverty}

Welfare and anti-poverty assistance is a shared responsibility among federal, state and local government; the private sector, community and faith-based organizations. Welfare policy must provide a strong safety net, while promoting work, responsibility, self sufficiency and dignity. I propose that we place time limits on

welfare benefits; require able-bodied welfare recipients to get a job, attend school or train for work, require participating mothers to identify the fathers of their children so they could contribute to their support, and emphasize personal responsibility by requiring welfare recipients to sign an independence contract pledging to stay drug-free and keep their kids immunized in school. 